\title{
Osteocondensing lesion of the metacarpal revealing monostotic fibrous dysplasia
}

ERRAOUI Mariam*, AFILAL Saloua, TAHIRI Latifa, RKAIN Hanan and ALLALI Fadoua

Department of rheumatology B, Hospital El Ayachi, Sale, Morocco

A 62-year-old female patient was referred for exploring right hand tumefaction. This tumefaction goes back more than 6 months. There was no pain or trauma history nor fever or weight loss.

The physical examination found a mass on the right hand occupying the entire length of the third metacarpal. It was hard, painless on palpation, fixed to the deep plane, without inflammatory signs.

The standard X-ray showed osteo-condensation of the whole third metacarpal (Figure 1). The computed tomography (CT) showed a third metacarpal hypertrophy with cortical thickening, without periosteal reaction or bone lysis, making strongly evoke fibrous dysplasia (Figure 2). No surgical treatment was indicated, only monitoring every 6 months was recommended.

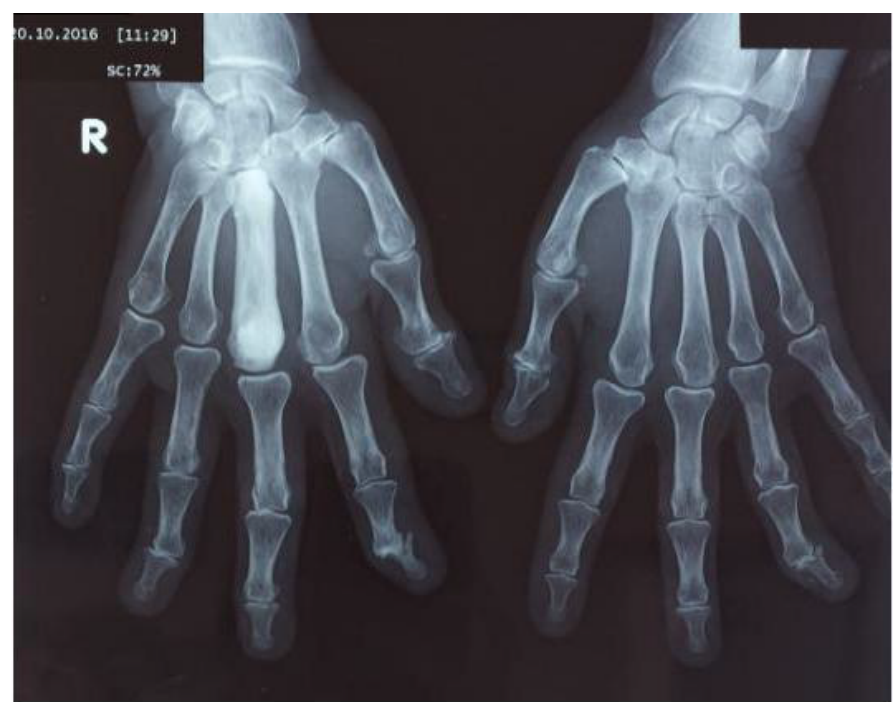

Figure 1. Radiograph of the face of both hands showing the appearance of osteocondensation occupying the whole 3 rd right metacarpal.

Copyright: (C)2017 Mariam E. This is an open-access article distributed under the terms of the Creative Commons Attribution License, which permits unrestricted use, distribution, and reproduction in any medium, provided the original author and source are credited.
Fibrous dysplasia is a sporadic bone disease, representing $0.8 \%$ of all primary bone tumors. It is a benign lesion, often asymptomatic. It can affect one bone (monostotic) or several bones (polyostotic). The monostotic form mainly affects the ribs, but hardly ever touches the hand.

During skeletal formation and growth, lesions of fibrous dysplasia are developed and they have a variable natural evolution. The etiology has been linked to an activating mutation in the gene that encodes the a subunit of stimulatory $\mathrm{G}$ protein $(\mathrm{Gs} \alpha$ ) located at 20q13.2-13.3 This malignity transformation is rare. Clinical observation and patient education if asymptomatic lesion is the unique treatment required.

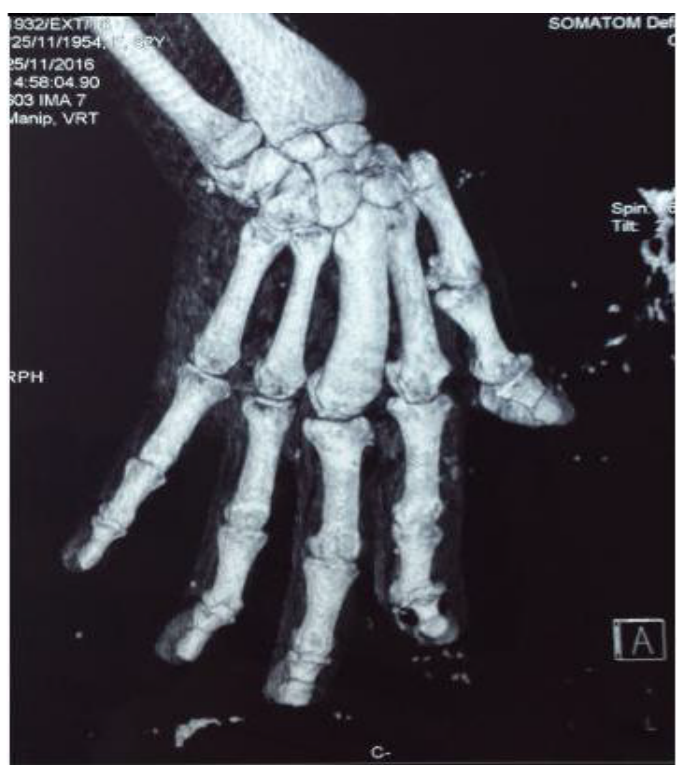

Figure 2. CT and 3D reconstruction of the right hand showing bone hypertrophy and cortical thickening of the third metacarpal.

Correspondence to: ERRAOUI Mariam, Department of rheumatology B, Hospital El Ayachi, Sale, Morocco, E-mail: mariama_erraoui@yahoo.fr

Received: August 01, 2017; Accepted: August 11,2017; Published: August 14, 2017 